\title{
FAMILIAS, RETORNOS EDUCATIVOS Y CLASES SOCIALES. VALORIZACIÓN DE CAPITAL CULTURAL Y ESTRATEGIAS ESCOLARES DE CLASE MEDIA Y CLASE TRABAJADORA EN CÓRDOBA (ARGENTINA)
}

\author{
FAMILIES, EDUCATIONAL REWARDS AND SOCIAL \\ CLASSES. CULTURAL CAPITAL VALORIZATION \\ AND SCHOLAR STRATEGIES OF MIDDLE CLASS \\ AND WORKING CLASS IN CÓRDOBA (ARGENTINA)
}

\author{
Gonzalo Assusa \\ Universidad Nacional de Córdoba, Argentina \\ gon_assusa@hotmail.com \\ Cecilia Inés Jiménez Zunino \\ Universidad Nacional de Córdoba, Argentina \\ ceciliazunino@hotmail.com
}

\begin{abstract}
Cómo citar / Citation
Assusa, Gonzalo y Jiménez Zunino, Cecilia Inés (2017). "Familias, retornos educativos y clases sociales. Valorización de capital cultural y estrategias escolares de clase media y clase trabajadora en Córdoba (Argentina)". OBETS. Revista de Ciencias Sociales, 12(2): pp-pp. 303-335.

doi:10.14198/OBETS2017.12.2.01

\section{Resumen}

Este texto analiza las estrategias de inversión y valorización del capital cultural en familias de clases media y trabajadora. Desde la teoría de la práctica de Pierre Bourdieu, y utilizando metodología que combina técnicas multivariadas (ACM) y entrevistas en profundidad, realizamos un análisis comparado de las apuestas escolares de las posiciones intermedias del espacio social de Gran Córdoba (Argentina). El objetivo es complejizar el análisis sobre las recientes dinámicas de desigualdad social, y desplazar la mirada desde la noción
\end{abstract}


de retornos educativos hacia las lógicas de inversión, las disposiciones prácticas y los modos de reproducción social de las familias.

Palabras clave: clases sociales, espacio social, Gran Córdoba, inversiones escolares, mercado de trabajo, estrategias sociales

\section{Abstract}

The current document analyzes the strategies of cultural capital investment and valorization of the middle and working class families. From the Pierre Bourdieu's theory of practice, and using methodology that combines multivariate techniques (ACM) and in-depth interviews, we conducted a comparative analysis of school investments in the intermediate positions of the social space of Gran Córdoba (Argentina). The goal is to open the analysis of the recent dynamics of social inequality and to shift the focus from the notion of educational returns to the investment logic, practical dispositions and social reproduction modes of the families.

Keywords: Social classes, social space, Gran Córdoba, school investments, labour market, social strategies.

\section{Extended abstract}

The current document seeks to analyze the strategies of cultural capital investment and valorization of the middle class and working class families on the social space in Gran Córdoba, Argentina. The objective of this study enables a more complex analysis in the context of the recent dynamics of social inequality and to displace the point of view from the notion of educational rewards towards the logics of investment, practical dispositions and the ways of family social reproduction.

The main conceptual coordinates of approach in this study are situated on the theory of practice of Pierre Bourdieu and his proposal to understand the processes of social reproduction and inequality. To that end we refer to the notions of social space, cultural capital, strategies of social reproduction, ways of reproduction and ways of generation.

We propose these perspectives from what we understand are some of the conceptual limitations of the notion of educational rewards: first, the standardization of labor insertion formats, logics and valorization periods and segments of working market deeply dissimilar between different positions in the social space. Second, the limited tools to acknowledge the extra-economic interests in school investments. We considered this are the dimensions to analyze in order to explore the heuristic potentialities of our study about the cultural capital valorization and the educational strategies from a social trajectories perspective.

To that end, and from a relational perspective that seeks to explain the double dimension of the social life, our analysis starts from the construction of the social space of classes and their statistical description, from a data processing of the household and individual statistical basis for the third quarter of 2003 and 2013 EPH- INDEC, bringing up a combination of techniques of factorial analysis and classification: multiple correspondence analysis (ACM) and ascending hierarchical classification (CJA). 
From the theoretical classes resulting from the analysis and processing combined with the conceptual proposal detailed above, we selected 43 representatives of families of different classes, who were conducted in-depth interviews along a wide range of practices, meanings and resources (housing, educational, labor, sociability, domestic and technological consumption strategies). In this paper we investigate in further depth the labor insertions of home referents, their spouses, ancestors and successors, considering their temporary nature, continuity and disruptions related to family cycles, their school careers and strategies that families tend to their younger members: sort of postpone job placements of children, sort of young members formation of new families, etc. For this article we undertook a comparative and relational exercise with interviews representatives whose families were classified into the middle and working classes. Beyond this, the construction of interpretive hypotheses constantly refers to all positions of social space as well as production data from an articulated variety of research techniques and empirical materials.

The statistical processing provides several indicators that enable the description of the social space of Gran Córdoba in terms of social conditions unequally exposed to scarcity and instability that enable accumulation mechanisms dissimilar to each other. In this context, we found that middle-class families tend to orient their school strategies in a practical belief of a slowness of the learning process that continues beyond instances of higher education (tertiary or grade). This path of constant investments in school certification only decrease when agents achieve consolidate labor positions (positions in teaching, won contests in the judicial system, etc.).

The slowness and perseverance in educational processes corresponds to the time of accumulation of school capital, at long term, establishing a sort of homology practice between work and school fields in the paths of the role models in these families. Therefore, this "patience" and "perseverance" would move from the school to the labor market in search of appropriate job placements regarding the former expectations.

Meanwhile, among working-class families, the form of cultural capital incorporated as technical (and applicable) knowledge appears as the dominant pattern of their school and labor strategies. Stories about learning experiences at work take a "practical" format and usually opposed to "theoretical" type of knowledge: the trade (construction, mechanical, industry) is learned by "doing", "watching and wondering." All these evaluations and justifications value the initiative and curiosity as key working tools.

Contrary to what indicates the prejudice of "short planning" that stands on families of popular classes, we found that the moral and financial sacrifice of parents to support their children's education acquires reasonableness with a projection of educational rewards in the very long term assurance of school, work and social destiny of their children. This logic reactivates the question of belief -among the referents of this social class-, in the substantial nature of educational credentials and their exemption from devaluation processes. 
Contrasts between both classes demonstrate differential valuations between families (even among those having different paths within the same class). Academic, instrumental, selfless and practical meanings assigned to knowledge and school qualifications, as well as academic, disciplinary and personal relationships forming roles assigned to school life get involved with career paths that set these capitals on labor market segments whose logic of selection are different (from the neighborhood networks of personalized reciprocity to public contests of state positions access).

Together, this wide range of processes seem to modify the distances in the social space, although with "contrasting tendencies" in different areas of social life. The configuration of the unequal distribution of cultural capital -which articulates, in the logic of its realization, the school market and the labor market- enabled, in the reading of the family long-term trajectories, an interpretation in terms of reconfiguration and reproduction of inequalities. This is evidenced by the simultaneous transmission of resources and of tools for its valorization, transmission of capital and habitus that brings up in bets, insertions and "rewards" with complex balances and collective efforts of family life.

\section{INTRODUCCIÓN}

Los años transcurridos desde el comienzo del siglo XXI en América Latina y en Argentina han sido interpretados de manera global por buena parte de la bibliografía sociológica como un proceso de "achicamiento de las brechas" y "disminución de las desigualdades" (Kessler, 2014; 2015; Benza, 2016) entre las clases sociales de la gran región intermedia de la estructura social. En este proceso, el relativo aumento salarial, el mejoramiento de niveles de educación y la denominada "caída de los retornos educativos" (Lustig, López-Calva y Ortiz-Juárez, 2011) han jugado un rol protagónico.

El presente texto tiene como objetivo el análisis de las estrategias de inversión y valorización del capital cultural en el mercado de trabajo en familias de clase media y clase trabajadora en Gran Córdoba (Argentina), en aras de aportar datos y complejizar los análisis del debate sociológico sobre las recientes dinámicas de desigualdad social. Para ello, desplazaremos el foco de atención desde los retornos educativos hacia una mirada sobre las lógicas de inversión, las disposiciones prácticas y los modos de reproducción social de las familias en relación a la definición de estrategias escolares, desde una perspectiva que reconstruya su configuración histórica en trayectorias sociales.

El trabajo comienza definiendo las principales coordenadas conceptuales desde las que abordamos nuestro análisis: la teoría de la práctica y su propuesta para comprender los procesos de reproducción social y desigualdad. Luego definimos las implicaciones metodológicas para la realización de un procesamiento estadístico y la reconstrucción de trayectorias con una perspectiva acor- 
de a la mirada relacional de la realidad social. A continuación, exponemos algunas de las principales características relevantes de la desigual distribución de los recursos en el espacio social de Gran Córdoba a partir de un análisis de fuentes de datos estadísticos, describiendo las condiciones estructurales desde las cuales estas familias desarrollan sus estrategias de reproducción social ${ }^{1}$. Acto seguido, reconstruimos las trayectorias sociales de los referentes de hogar, sus antecesores y sucesores (en caso de haberlos) con el objetivo de analizar la variabilidad fenoménica de sus apuestas, inversiones y elecciones en relación a la valorización del capital cultural en sus familias. Finalmente, proponemos algunas conclusiones volviendo sobre la propuesta teórica de desplazamiento de la mirada y su aporte para pensar la reconfiguración de las desigualdades en nuestro contexto local.

\section{COORDENADAS TEÓRICO-METODOLÓGICAS}

\section{Procesos, modos y estrategias de reproducción social}

La teoría de la práctica adopta el sistema estructural de relaciones como base epistemológica para el análisis de la desigualdad social (Baranger, 2004). Un conjunto diverso de capitales (económico, cultural, social y simbólico) se distribuye de manera desigual en el espacio social y, de esta forma: a) configura las posiciones de clase que definen condiciones objetivas y posibilidades diferenciales de acción para los agentes que las ocupan; y b) le otorga estructura e inteligibilidad al espacio como campo de relaciones de fuerza y sentido que asignan valores relativos (relacionales) a dichas posiciones y a sus ocupantes ${ }^{2}$.

La perspectiva que encara los procesos de reproducción social define dos aristas analíticas complementarias. Toma como punto de partida la descripción del volumen y estructura patrimonial de las familias (Bourdieu, 1998), para, acto seguido, analizar las disposiciones prácticas durables, regulares y trasladables de los agentes (habitus) ${ }^{3}$. Estas se forman a partir de la incorporación de determinadas posiciones en un espacio relacional y transfieren al cuerpo y a los esquemas mentales del agente tanto las posibilidades estratégicas como

\footnotetext{
${ }^{1}$ La producción de datos de este artículo se enmarca en proyectos colectivos, titulados: "Las clases y su reproducción en el espacio social cordobés (2003-2013)" y "Estrategias de reproducción social en familias cordobesas: dinámicas recientes", dirigidos por la Dra. Alicia Gutiérrez y el Dr. Héctor Mansilla.

${ }^{2}$ Para un resumen de las discusiones teóricas, metodológicas y empíricas acerca de la particular elaboración del espacio de las clases sociales que construimos desde nuestro proyecto, ver Gutiérrez y Mansilla, 2015).

${ }_{3}^{3}$ Para una crítica sobre el límite del carácter trasladable del habitus, ver Lahire (2004).
} 
los límites objetivos (en forma de horizontes de lo pensable, aceptable o deseable; Bourdieu, 2010).

El conocimiento de estas posiciones y de su efecto estructural en el marco de un sistema relacional, nos permite acceder a la comprensión de las diferencias de clase plasmadas en las estrategias y trayectorias de las familias de nuestro estudio. Construir epistemológicamente el conjunto de relaciones y sentidos que componen la realidad social como un proceso de reproducción abre interrogantes que nos alejan de una imagen estática de la vida social. Primero, en dirección a analizar la formación o socio-génesis de los grupos, con sus respectivos procesos de acumulación. Y segundo, en dirección a indagar sobre la continuidad o discontinuidad de sus relaciones, disposiciones y apuestas como claves de lectura sobre lo posible, lo necesario, lo apropiado y lo deseable para los agentes. Tal como sostienen Vommaro y Wilkis (2015), esta propuesta metodológica procesual se ubica en la tradición de Thompson (1989) y en la investigación acerca de la formación social de las clases en la historia. Desde esta perspectiva, los procesos de reproducción social no constituyen dinámicas autónomas y mecánicas: se corporizan en un conjunto muy complejo y articulado de estrategias que tiene por sujeto a las familias (Bourdieu, 2011), y que tiene por objetivo la mejora o el mantenimiento de las posiciones sociales adquiridas (Gutiérrez, 2005), y en el mismo acto, la reproducción de la sociedad como totalidad (de su sustento material, de sus relaciones y de sus construcciones simbólicas; Mauger, 2013a). Los modos de reproducción familiar (Mauger, 2013b) implican las diversas formas en que estas acciones se adaptan a patrimonios recursivos diversos, es decir, a las posiciones que estas familias ocupan en el espacio social y a las condiciones que encuentran para valorizar los capitales con los que cuentan.

Con el objetivo de observar la estructuración de las relaciones en el marco de lo que llama modos de reproducción, Mauger propone la categoría de modo de generación, en tanto regulación de la transmisión, intercambio, disputa y distribución de recursos entre generaciones sociales. Este concepto permite visibilizar los modos en que se oponen y alían, regulan el conflicto y se limitan las alianzas posibles entre "viejos" y "jóvenes" de un espacio (Mauger, 2013a; Beaud y Pialoux, 2015). Modo de generación (en el sentido de génesis) de los agentes y sus disposiciones (Martín Criado, 1998), que se vuelve identificable y relevante justamente cuando el contexto estructural y los instrumentos de reproducción se transforman y mutan de manera sustancial. Estas disputas y relaciones intergeneracionales se presentan de modo paradigmático en las familias, agentes esenciales para el desarrollo de energías físicas, morales e intelectuales de los agentes. En las familias se da la transmisión de recursos morales 
y culturales, que toman lugar durante la infancia y los años de escolarización. Constituyen, además, el lugar del pensamiento estratégico para la movilización de recursos, con redes protectoras contra la dura competencia (Bertaux, 1995).

En este punto se vuelven particularmente relevantes las denominadas estrategias escolares -fundamentalmente lo que atañe a las elecciones, esfuerzos y sostenimiento de inserciones escolares para los hijos-, como una de las prácticas vitales en las sociedades contemporáneas en torno a garantizar la transmisión de los capitales familiares (especialmente el cultural), como así también de las condiciones y disposiciones para la valorización de dichos recursos. De igual modo (y de manera relacional) es necesario prestar atención a las estrategias de inserción laboral, tomando al mercado de trabajo como instrumento de reproducción central, espacio de valorización y realización del capital cultural (en sus estados institucionalizado e incorporado) y, por lo tanto, motor fundamental de la desigualdad social.

\section{Propuesta metodológica: la articulación de técnicas multivariadas y el análisis de trayectorias sociales}

En el presente texto combinamos metodología cuantitativa y cualitativa, pretendiendo dar cuenta de: 1) la desigual distribución de los recursos en el espacio social y los efectos estructurales del sistema relacional; 2) la diversidad fenoménica que encarnan los sistemas de prácticas articulados a nivel familiar que aquí llamamos, siguiendo a Bourdieu (2011), estrategias de reproducción social; 3) la sedimentación histórica de recursos y disposiciones a partir de la incorporación de las condiciones objetivas en forma de esquemas para la práctica; y 4) las significaciones, sentidos vividos y retraducciones simbólicas de desigualdades sociales en forma de "diferencias" culturales, distinciones y fronteras (en nuestro caso, específicamente referidas a las estrategias escolares y a las inserciones en el mercado de trabajo).

Como hemos explicitado con mayor detalle en artículos previos (Gutiérrez y Mansilla, 2015; Freyre y Assusa, 2014), para la construcción del espacio de las clases sociales y su descripción estadística, procesamos los datos de las bases Hogares e Individuos correspondientes al tercer trimestre de 2003 y 2013 de la EPH-INDEC poniendo en juego una combinación de técnicas de análisis factorial y clasificación: análisis de correspondencias múltiples (ACM) y clasificación jerárquica ascendente (CJA) .

${ }^{4}$ Con las técnicas multivariadas como el ACM se analizan relaciones de interdependencia, clasificando unidades de análisis y variables, de manera exploratoria, para ordenar los datos y construir hipótesis, tipologías e interpretaciones (López-Roldán, 1996; Baranger, 
El resultado de este procesamiento derivó en la construcción de un espacio social con un corte de cuatro clases ${ }^{5}$ cuya representación gráfica puede observarse en el Diagrama 1. La estructura del espacio social, de acuerdo a las variables consideradas, puede interpretarse como la desigualdad extrema de un conjunto de familias en las posiciones más precarias de todo el espacio (en el cuadrante inferior izquierdo del diagrama), y de un conjunto de familias que representan los grupos de mayor concentración de poder ("elite social", en el cuadrante superior derecho del diagrama). En la región intermedia del espacio, un heterogéneo grupo de familias divididas en dos clases, cuyas características (como desarrollamos en el apartado siguiente) resultan las más interesantes y relevantes para este estudio.

A partir de las clases teóricas resultantes del procesamiento entramado con la propuesta conceptual detallada anteriormente, seleccionamos 43 referentes $^{6}$ de las familias de las distintas clases, a quienes realizamos entrevistas en profundidad que recorrieron una amplia variedad de prácticas, sentidos y recursos (estrategias habitacionales, educativas, laborales, de sociabilidad, domésticas y de consumos tecnológicos). La muestra de entrevistas se construyó con un criterio de selección que articulaba disponibilidad de contactos entrevistables, la representatividad del perfil definido por el procesamiento estadístico para cada una de estas clases (y sus fracciones) y la variación y diversidad teórica en relación a ejes definidos como relevantes (inserciones en ramas de actividad, nivel educativo, edad, sexo, configuración familiar, etc.).

En este texto indagamos con mayor profundidad las inserciones laborales (de los referentes de hogar, sus cónyuges, antecesores y sucesores), considerando su temporalidad (continuidad e interrupciones en relación a los ciclos

2004; Gutiérrez y Mansilla, 2015). Esto permite observar la desigualdad en términos de los efectos estructurales del sistema de relaciones entre las variables y sus respectivas modalidades. La complementación con la CJA permite distinguir clases "recortadas" en el espacio multidimensional.

${ }^{5}$ Para la investigación marco hemos realizado un corte óptimo en cuatro clases (clase alta o elite, clase media, clase trabajadora y clase vulnerable) de las que tomaremos, en este escrito, las de la región intermedia. Las que denominamos clase media y clase trabajadora han sido asimiladas como una gran clase media en estudios que se centran solo en la variable ingresos para la construcción de clases sociales.

${ }^{6}$ El Referente de Hogar es el miembro que, por sus propiedades laborales, nivel educativo y posición en la configuración familiar, permite enclasar al grupo familiar (Gutiérrez y Mansilla, 2015), haciendo extensivo su patrimonio al hogar como colectivo. Para ver la discusión acerca de tomar al jefe de hogar como representativo para las características del hogar, ver Torrado (1998). Nuestra opción fue la de recategorizar los "Jefes de Hogar" de la EPH, seleccionando nuestros propios referentes, a partir de la consideración de un criterio unificado y coherente (con los principios antes explicitados), tanto en el procesamiento estadístico como en la selección de la muestra para el abordaje cualitativo. 
familiares). Asimismo, enfocamos en las trayectorias escolares de todos los miembros y las estrategias a las que las familias inclinan a sus miembros más jóvenes: inserciones laborales más o menos postergadas de los hijos, formación de familias de destino más o menos tempranas, etc. A partir de este eje, emprendimos un ejercicio comparativo y relacional del material de las entrevistas a referentes cuyas familias fueron clasificadas en las clases media y trabajadora (ver Cuadro 1 en los anexos). Más allá de este recorte, la construcción de hipótesis interpretativas remite permanentemente al abordaje de las demás posiciones del espacio social.

Las trayectorias se presentan como clave de acceso metodológico a las ataduras de temporalidad que reúnen posición / disposición / toma de posición. El habitus, que opera de manera regular y homóloga en la práctica, se forma en un sentido posicional, no sólo en relación a condiciones sociales diferenciales (entre la clase media y la clase trabajadora). También lo hace en el marco de un proceso histórico de adaptación a la estructura de capital de cada clase y a las configuraciones familiares a las que estas posiciones de clase se asocian.

Los relatos de prácticas de los entrevistados, analizados a la luz de las transformaciones estructurales, permiten captar la lógica de acción (Bertaux, 2005) en el desarrollo de las historias familiares. Este proceso analítico sostiene una permanente vigilancia para evitar caer en la tentación de una ilusión biográfica que se torne epistemológicamente autosuficiente (Bourdieu, 1997), desanclada de las condiciones de posibilidad de la posición de clase del agente y de las articulaciones familiares que implica la confección de las estrategias de reproducción social.

\section{RESULTADOS Y DISCUSIÓN}

\section{Caracterización de las posiciones estructurales de clase media y clase trabajadora}

En el espacio social se representan los principales factores de diferenciación de una nube de puntos que se constituye a partir de una estructura desigual de múltiples recursos, captada por diversas variables, modalidades y asociaciones. Llamamos clase trabajadora ${ }^{7}$ a la posición de clase ubicada en el cuadrante infe-

\footnotetext{
${ }^{7}$ La elección de esta nominación no se relaciona con la esfera del trabajo como praxis constituyente, ni con la venta de la fuerza de trabajo como estrategia de reproducción privilegiada (elemento que no permite distinguir claramente a esta del resto de las posiciones del espacio social). Antes bien, responde a motivos de comunicación y diálogo con otras investigaciones o perspectivas: hablamos de clase "trabajadora" para identificar a lo que tradicionalmente fue denominado como "clase obrera", haciendo referencia tanto a un
} 
rior derecho del plano factorial -en el Diagrama 1, "clase media-dominada"-, con un 42\% del total de familias de la base para el año 2013.

Las asociaciones de esta clase la definen en relación a ingresos medios y bajos, con referentes insertos fundamentalmente en las ramas de la construcción, la industria, el transporte y la logística, muchos de ellos en condición de autónomos y en establecimientos pequeños del sector privado. La clase se caracteriza, además, por una fuerte asociación a situaciones conyugales (unidos o casados), a configuraciones familiares con 4 o más miembros y una alta presencia de menores de 10 años (lo cual establece un peso determinante en cuanto a sus tareas de reproducción doméstica). El capital escolar de sus referentes tiende a ser bajo (el nivel educativo va de primario incompleto a secundario incompleto), más aún si se toma como referencia los niveles educativos de la clase media.

Denominamos clase media ${ }^{8}$ a la segunda de las posiciones tomadas para el artículo, ubicada en el cuadrante superior izquierdo con más del 38\% de los hogares para 2013 -en el diagrama 1, "clase media-dominante"-. Esta clasificación de familias se caracteriza por hogares pequeños o unipersonales. Sus ingresos se asocian a niveles medios y altos y sus referentes se ocupan, fundamentalmente, en puestos de técnicos o asalariados profesionales, en la condición de empleados y, en menor medida, de jefes, en las ramas de educación, salud y gestión jurídico-administrativa. Las inserciones laborales se asocian al sector estatal, en establecimientos medianos (de 6 a 40 personas o de más de 40), con cobertura médica, social y laboral. Su alta calificación resulta coherente con una fuerte acumulación de capital cultural institucionalizado (nivel universitario completo y, en menor medida, incompleto).

Tomamos algunos indicadores socio-laborales (ver Tabla 1) para ilustrar, primero, la desigual distribución de los recursos, las "recompensas" (Benza, 2014) y los "retornos" (Lustig et al., 2011); y segundo, la dinámica de las brechas y las distancias en el período que abarca desde 2003 a 2013. Las tasas de

acervo histórico, político y cultural, a trabajadores operarios de distintas ramas que especificamos a continuación y que componen, en varios sentidos, la fracción mejor posicionada de las clases populares.

${ }^{8}$ A pesar del extenso debate sobre la existencia de las clases medias y de sus fronteras, asumimos que presentan formatos, si bien cambiantes, posibles de definir sociológicamente. En este apartado atendemos a la distribución de los distintos tipos de recursos considerados para la construcción del espacio social de Gran Córdoba, que permiten identificar posiciones intermedias, y que configuran específicas condiciones de posibilidad para la elaboración de estrategias de reproducción social. Los casos empíricos tomados para las entrevistas se corresponden, grosso modo, con las denominadas por Goldthorpe (1992) como clases de servicios, aunque sin incluir a las posiciones más altas de la élite (Savage et al., 2013). 


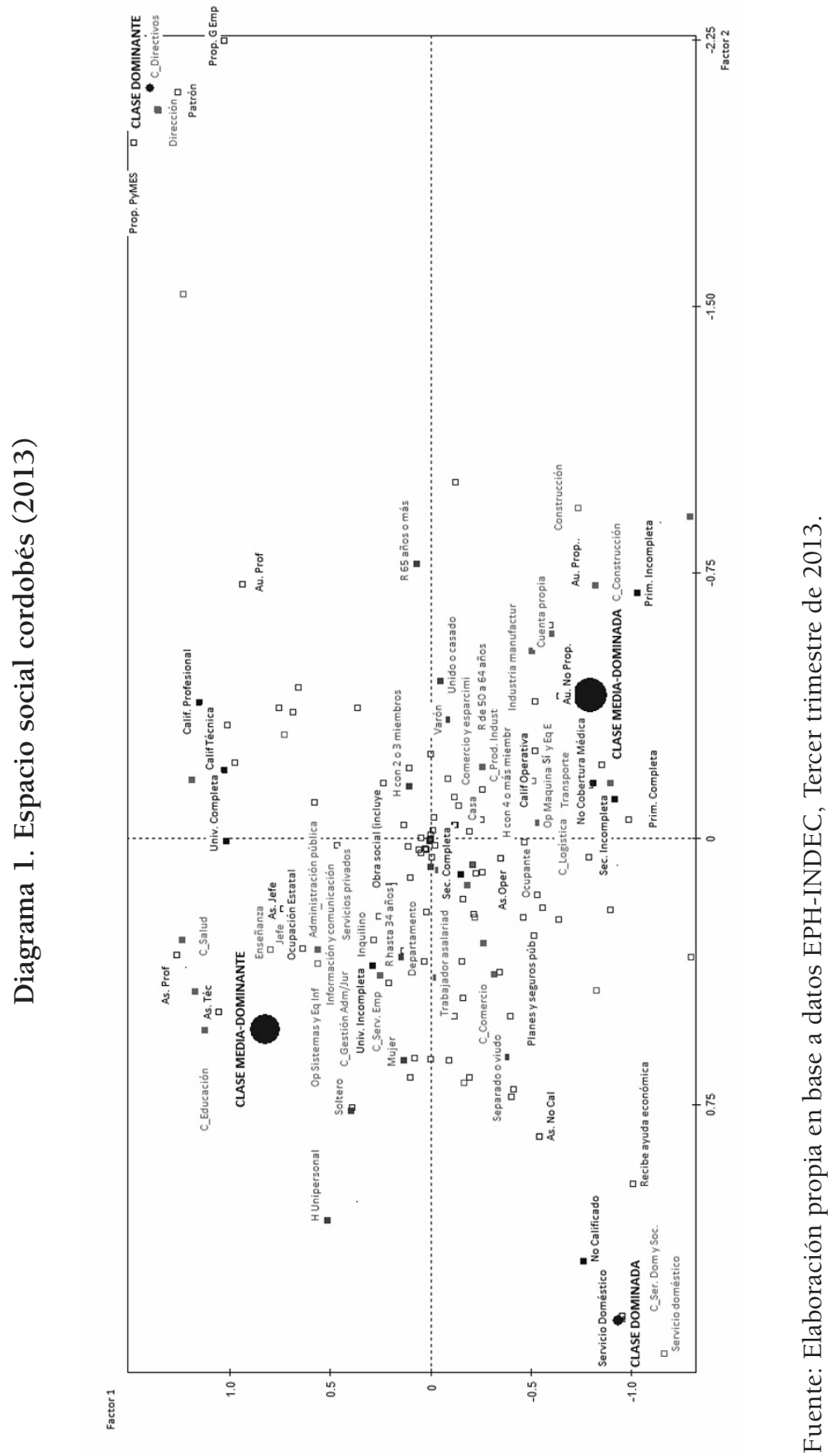


desocupación, sub-ocupación y empleo informal cayeron para todas las posiciones durante la post-convertibilidad ${ }^{9}$ (Neffa, Oliveri y Persia, 2010; Palomino y Dalle, 2012; Kessler, 2014) aunque su tendencia estructural afecta mucho más a hogares de clase trabajadora (rasgo que se ha sostenido en el tiempo, cuando no se ha profundizado). Un proceso de asociación equivalente puede observarse en relación a los indicadores de calificación laboral y seguridad social: un mejoramiento de las condiciones de vida de la clase trabajadora que, sin embargo, reproducen las brechas de desigualdad o las disminuyen muy levemente. Por último, la acumulación de capital escolar entre los referentes de hogar y la asistencia a establecimientos escolares de gestión privada de los hijos de familias de ambas clases (como indicador de estrategias escolares) en el período 2003-2013 muestran una disminución de las desigualdades en el acceso, particularmente pronunciada en el caso de este último indicador.

Tabla 1. Indicadores socio-laborales y educativos según Clase Social. Gran Córdoba. 2003-2013

\begin{tabular}{|c|c|c|c|c|}
\hline & \multicolumn{2}{|l|}{2003} & \multicolumn{2}{|l|}{2013} \\
\hline & $\begin{array}{l}\text { Clase } \\
\text { Trabajadora }\end{array}$ & Clase Media & $\begin{array}{l}\text { Clase } \\
\text { Trabajadora }\end{array}$ & Clase Media \\
\hline Desocupación & $12,4 \%$ & $7,7 \%$ & $8,4 \%$ & $3,5 \%$ \\
\hline Subocupación demandante & $8,9 \%$ & $4,7 \%$ & $4,2 \%$ & $1,3 \%$ \\
\hline Informalidad & $41,3 \%$ & $12,8 \%$ & $24,7 \%$ & $8,5 \%$ \\
\hline No-calificación laboral & $24,7 \%$ & $6,3 \%$ & $18,9 \%$ & $4,6 \%$ \\
\hline $\begin{array}{l}\text { Mediana de ingreso por clase / } \\
\text { Mediana de ingreso total }\end{array}$ & 0,68 & 2,42 & 0,75 & 1,75 \\
\hline Relación de medianas & \multicolumn{2}{|l|}{0,28} & \multicolumn{2}{|l|}{0,42} \\
\hline Relación de medias & \multicolumn{2}{|l|}{0,34} & \multicolumn{2}{|l|}{0,43} \\
\hline $\begin{array}{l}\text { Cobertura médica de la } \\
\text { población }\end{array}$ & $29 \%$ & $86 \%$ & $63 \%$ & $94 \%$ \\
\hline $\begin{array}{l}\text { Nivel educativo } \\
\text { universitario/terciario } \\
\text { completo }(\mathbf{R H})\end{array}$ & $2,9 \%$ & $56,4 \%$ & $5,6 \%$ & $52,6 \%$ \\
\hline $\begin{array}{l}\text { Hijos que asisten o asistieron a } \\
\text { establecimientos educativos } \\
\text { privados ( } 5 \text { a } 25 \text { años) }\end{array}$ & $11,5 \%$ & $44,9 \%$ & $24,9 \%$ & $46,4 \%$ \\
\hline
\end{tabular}

Fuente: Elaboración propia en base a datos EPH-INDEC, Tercer trimestre de 2003 y 2013

${ }^{9}$ Se denomina así a la etapa que se inicia en 2003, durante el gobierno de Néstor Kirchner, caracterizada por el cambio del modelo económico, que, entre otras medidas, desancló el valor nominal de un peso equivalente a un dólar, vigente durante la década de 1990. 
Más allá de la exhaustividad con la que podría caracterizarse cada una de estas áreas de la vida social, observamos ciertas tendencias generales: condiciones sociales desigualmente expuestas a la precariedad y la inestabilidad, que habilitan mecanismos de acumulación disímiles entre sí. Volveremos sobre esta cuestión en el análisis de las trayectorias.

La literatura especializada ha prestado particular atención a dos factores de transformación de la desigualdad durante la primera década del siglo XXI en América Latina: el aumento de los niveles educativos de la población y un proceso de achicamiento de las brechas salariales (Lustig et al., 2011; Kessler, 2015; Benza, 2016). Este rasgo puede observarse también para el caso del espacio social de Gran Córdoba (ver Tabla 1). Así, Lustig y colaboradores señalan que la caída de los retornos educativos en Argentina se basó fundamentalmente en una reorientación del mercado laboral hacia los sectores de baja calificación y trabajo-intensivos, acompañada de otros factores como la recuperación del poder sindical, la caída del desempleo, el aumento de cobertura educativa y el desarrollo de importantes políticas de transferencia de ingresos -como la Asignación Universal por $\mathrm{Hijo}^{10}$ - (Lustig et al., 2011).

En este marco, el relevante incremento en los niveles de instrucción de la población registrado en el periodo de la post-convertibilidad no se tradujo necesariamente en una mejora de la calidad del empleo -los mentados retornos educativos-, sino que el mayor nivel educativo habría respondido a requerimientos de determinados sectores productivos y segmentos del mercado de trabajo (Salvia y Vera, 2013). Esta interpretación es complementaria a la tesis del aumento de la demanda de trabajadores menos calificados (Kessler, 2015). Sin embargo, para Kessler el sector de servicios requiere cada vez de mayores titulaciones, por lo que es necesario explicar también la disminución de los retornos educativos por la propia devaluación de los diplomas, la obsolescencia de las calificaciones o la desigualdad en la calidad de la formación de nivel superior (Lustig et al., 2011).

En este último punto se anticipan algunas de las limitaciones conceptuales de la noción de retornos educativos tal y como la hemos encontrado en las investigaciones referidas. En primer lugar, homogeneiza formatos de inserción laboral, lógicas y tiempos de valorización y segmentos del mercado de trabajo profundamente disímiles entre las distintas posiciones del espacio social. En segun-

\footnotetext{
${ }^{10}$ Asignación Universal por Hijo para la Protección Social (AUH): se trata de una política de transferencia de ingresos implementada por Decreto 1602/2009, y que alcanza específicamente a población de hogares cuyos padres están desocupados o en condiciones de informalidad.
} 
do lugar, otorga pocas herramientas para dar cuenta de lo que desde una economía general de las prácticas (Bourdieu, 1997; Baranger, 2000; Gutiérrez, 2010) podemos llamar los intereses extra-económicos en las inversiones escolares y el conjunto de sentidos vividos con el que se significan y justifican estrategias educativas que consumen buena parte de las energías y los recursos familiares, sin ofrecer "retornos" inmediatamente observables. Consideramos que estas son las dimensiones a analizar para explotar las potencialidades heurísticas de nuestro estudio acerca de la valorización del capital cultural y las estrategias educativas desde la perspectiva de las trayectorias sociales.

\section{Apuestas escolares de las clases media y trabajadora}

El relevamiento consistió fundamentalmente en la realización de entrevistas en profundidad a los referentes de familias de cada una de las posiciones de clase construidas en el análisis de procesamiento de datos estadísticos. En este escrito se analizan 19 entrevistas, seleccionadas de una muestra mayor, como se explicitó anteriormente (ver Cuadro 1). El material resultante del trabajo de campo presentaba indicios de importantes inversiones escolares (en esfuerzos, en dinero y en tiempo) de las familias tanto de clase media como de clase trabajadora. La opción por enviar a sus hijos a escuelas de gestión privada (especialmente a los más pequeños, después de "malas" experiencias con los mayores) es una práctica mucho más común (sea en términos efectivos, sea como pretensión, deseo o proyecto de los adultos) de lo que en primera instancia indicaba el procesamiento estadístico (las instituciones educativas a las que asisten los hijos de las familias de clases media y alta se asocian estructuralmente al sector de gestión privada en el nivel inicial y medio; Giovine y Jiménez, 2016) Asimismo, la elección de escuelas con ingreso restringido vía examen, aparece también como rasgo presente en las dos clases (aunque de manera más pronunciada en la clase media que en la clase trabajadora).

Existen, más allá de estas confluencias, diferentes modulaciones y divergencias en las lógicas de inversión y valorización del capital cultural (en sus distintas modalidades). Estas difracciones se relacionan estrechamente con las trayectorias sociales de los entrevistados (incluso dentro de la misma clase); con las expectativas depositadas en la institución escolar en tanto otorgante de títulos, de conocimientos incorporados (oficios), proveedora de capital social o incluso como institución civilizatoria -valoraciones de lo escolar centradas en las cuestiones de "conducta", de "educación" (en un sentido moral) o de "cultura" (Elias, 1988)-. 







\begin{tabular}{|c|c|c|c|c|}
\hline &  & 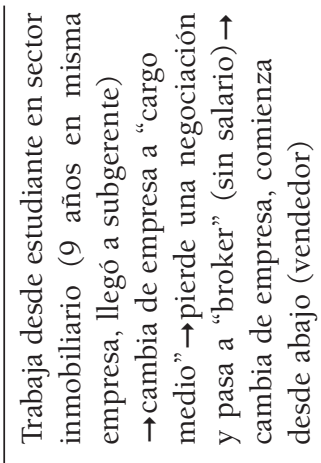 & 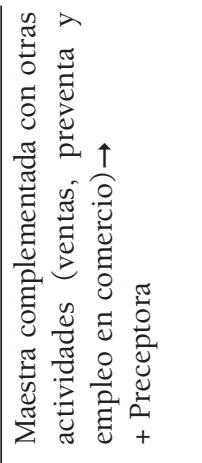 & 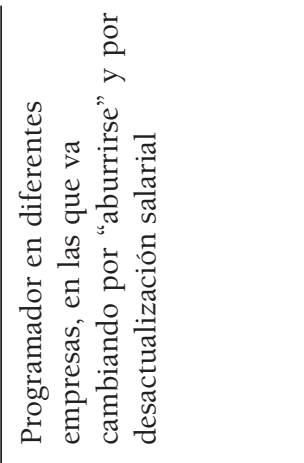 \\
\hline 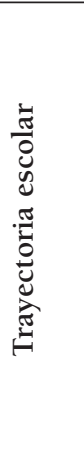 & 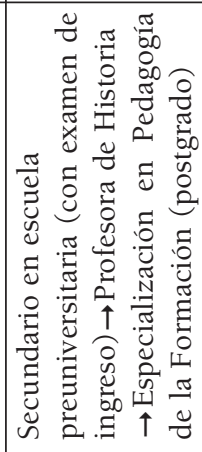 & 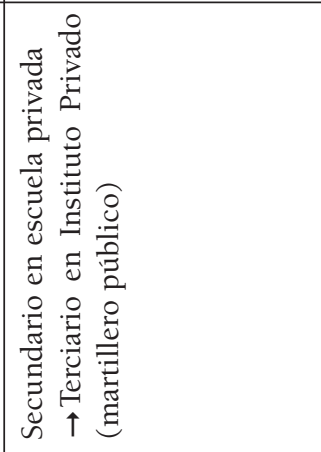 & 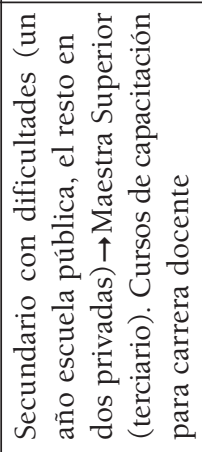 &  \\
\hline 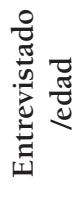 & 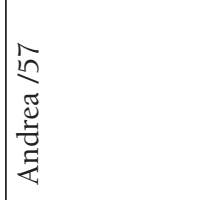 & 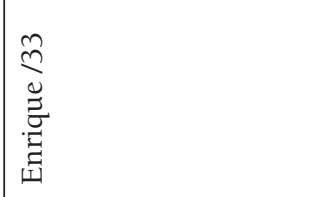 & 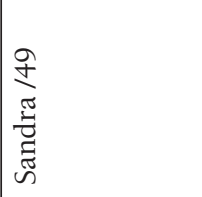 & 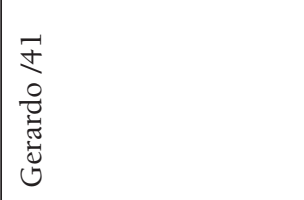 \\
\hline 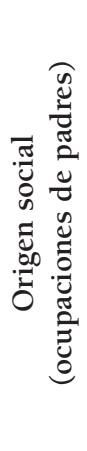 & 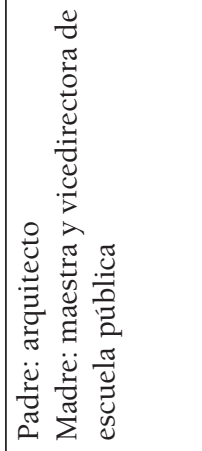 &  & 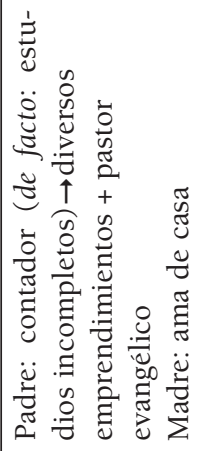 & 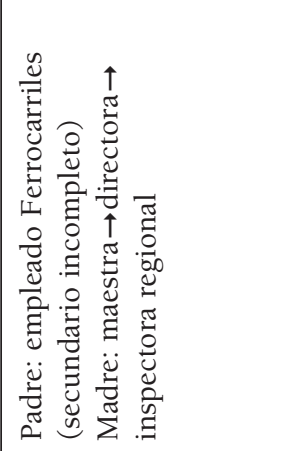 \\
\hline 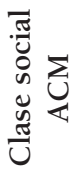 & \multicolumn{4}{|c|}{ 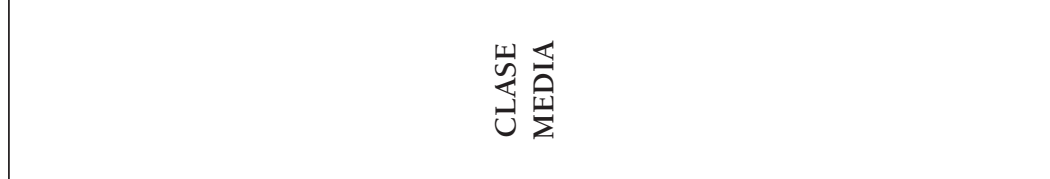 } \\
\hline
\end{tabular}









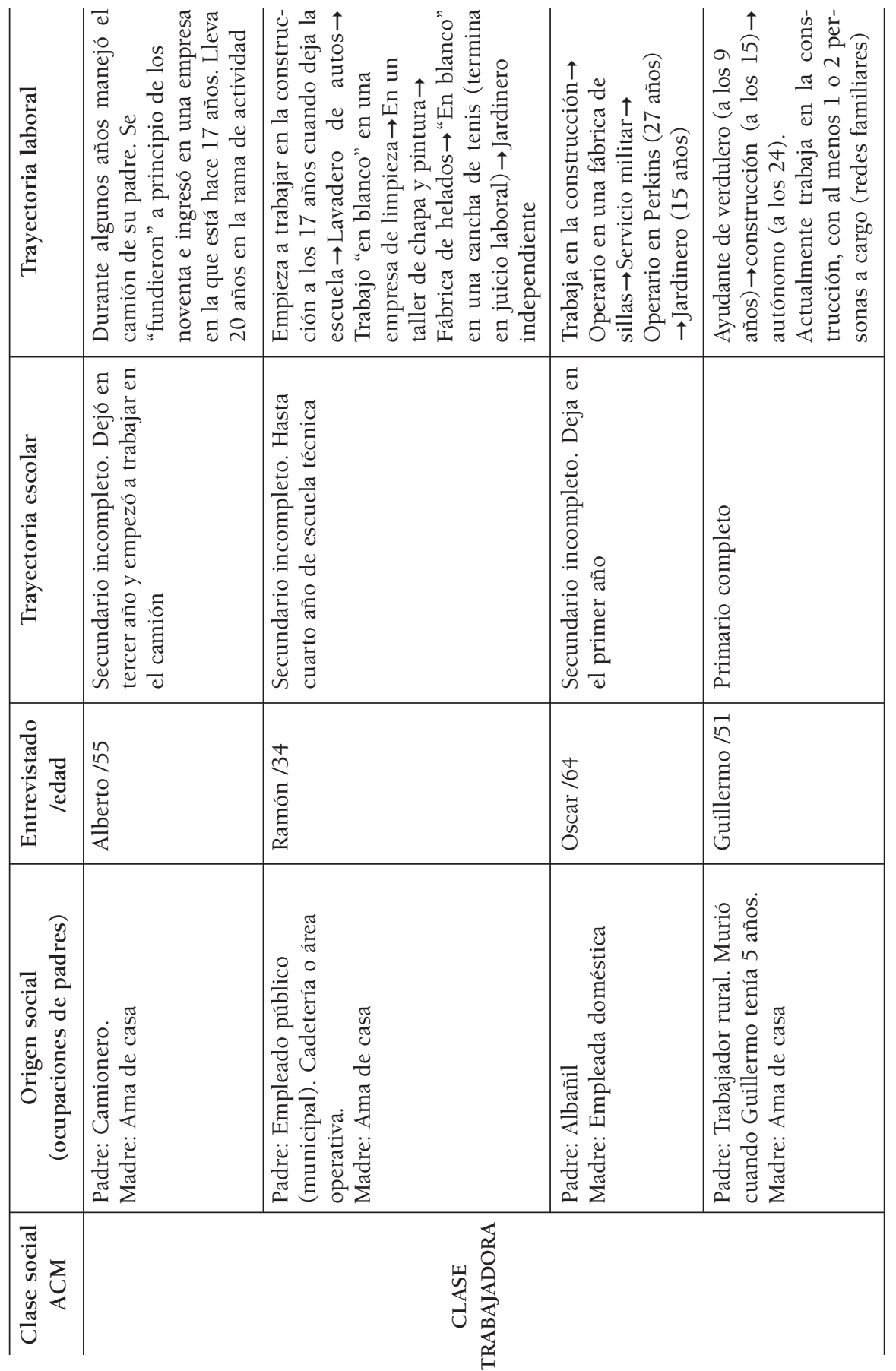

OBETS. Revista de Ciencias Sociales. Vol. 12, n. ${ }^{\circ}$ 2, 2017, pp. 303-335. DOI: 10.14198/OBETS2017.12.2.01 







\section{Inversión y valorización de capital cultural en el largo plazo}

Una primera instancia de diferenciación entre ambas clases toma cuerpo en la relación que estas familias establecen con el capital cultural (particularmente en su formato institucionalizado como titulaciones o certificados, es decir, como capital escolar) y sus pesos relativos en las estrategias de inserción, permanencia y promoción laboral.

Las familias de clase media entrevistadas compensan su déficit económico relativo ${ }^{11}$ con fuertes inversiones en capital cultural legitimado (escuelas con ingreso restringido por examen o escuelas privadas), bajo la expectativa de obtener recompensas acordes en el mercado de trabajo. Este horizonte se manifiesta en una búsqueda permanente de inserciones laborales cada vez más adecuadas y concordantes: con la formación específica realizada y las capacidades que ésta habilita, como la jerarquía laboral ("tener gente a cargo"), la asunción creciente de responsabilidades en la organización y la creatividad ("estar a cargo de diseño de productos"). El papel del salario, en cambio, se manifiesta como componente elíptico de sus argumentaciones, cuando no manifiestamente negado como criterio decisorio.

La escuela pública en Argentina ha sido caracterizada comúnmente como un espacio de encuentro inter-clase, ya sea en la relación de pares estudiantes o en la de docentes/estudiantes (Noel, 2009). En el caso de las familias de clase media esta dinámica se sostiene, aunque bajo la aspiración de encuentro con personas de posiciones con mayor patrimonio, construyendo a la escuela como fuente privilegiada de capital social (es el caso de alumnos becados en colegios con altos aranceles a los que asistían, por ejemplo, los hijos del gobernador y de terratenientes locales). Aquellos referentes que asistieron a establecimientos educativos con ingreso restringido por examen (preuniversitarios), naturalizan el peso del capital social allí generado para las inserciones posteriores.

La escuela, así, funciona como punto de contacto con otros sociales que empujan para "arriba" las pretensiones, evitando "achatar" la "actitud" y las conductas de los hijos. La pretensión de "ser como ellos", "aspirar a tener algo más, cosas materiales" se forma y moldea de una particular manera en el espacio escolar (a falta de una capitalización económica importante en las familias de origen, como se aprecia en el Cuadro 1).

${ }^{11}$ Dado que no entrevistamos a propietarios de pequeñas empresas, que podrían considerarse posiciones de pequeña burguesía, todos pertenecen a la fracción más rica en capital cultural. Algunos, no obstante, en la generación anterior -padres- poseen capital económico relativamente más importante que el cultural. 
En las trayectorias de los referentes suele haber una búsqueda sostenida en el tiempo de convergencia entre los estudios/titulaciones y las inserciones laborales. Esto habilita las valoraciones del capital cultural per se-como anclaje identitario, autoadscribiendo a una forma desinteresada (Bourdieu, 1997) del saber por el saber, y del reconocimiento de "la cultura y lo culto"- y de las certificaciones como símbolos de posicionamiento social en el orden meritocrático.

Las apuestas escolares, de esta manera, van anticipando y tramando las inserciones laborales presentes y futuras, a la vez que articulan las inversiones culturales complementarias que adquieren sentido en la lógica de apuntalamiento de carrearas burocráticas de largo plazo (la realización de cursos para sumar puntajes, postgrados para revalorizar o reorientar titulaciones de grado, etc.).

Existen, sin embargo, sutiles diferencias entre los referentes con una composición patrimonial orientada al capital cultural en su familia de origen -titulaciones universitarias que hayan producido inserciones profesionales específicas entre sus padres, como arquitecto, contador, químico, profesor universitario y secundario, con casos recurrentes de madres docentes-; y aquellos referentes que fueron "estimulados" a realizar inversiones escolares en su propia trayectoria, pero desde posiciones más ligadas a acumulaciones económicas medianas en origen (que capitalizaron en propiedades inmuebles y pequeñas o medianas empresas).

Entre estos últimos se percibe una tendencia a la valoración de las credenciales escolares en un sentido más estrictamente instrumental ${ }^{12}$, en tanto moneda de cambio para el mercado laboral. Es el caso de una entrevistada a quien "no le gustaba estudiar" y, aun así, inició una carrera docente: primero magisterio, luego completó como preceptora y en el momento de la entrevista planeaba concursar para vicedirectora. La insistencia de sus padres en que lograra la titulación (apuntalada desde el secundario para que terminara su escolaridad en colegios privados, tras haber tenido "dificultades" -repitencia- en una escuela pública), adquiere inteligibilidad en un contexto en el que sus propias inserciones habían estado signadas por la ausencia de un título habilitante: su padre (contador de oficio ${ }^{13}$ ), no poseía certificación profesional,

\footnotetext{
12 Sin pretender divisiones tajantes o excesivamente esquemáticas, proponemos una interpretación de la lógica de carácter más instrumental en oposición relativa a una lógica que se presenta como desinteresada o vocacional, no en tanto reproducción literal del discurso nativo, sino como reconocimiento de lógicas prácticas que, efectivamente, habilitan cursos de acción disímiles.

${ }^{13}$ Nos referimos a la práctica de llevar los papeles contables de negocios y campos, sin la efectiva titulación.
} 
aunque contaba con el favor de su hermano titulado para validar legalmente su trabajo. En otro de los casos, las familias materna y paterna poseían diversos emprendimientos (estación de servicio, ferretería, campos) y el referente entrevistado ingresó como estudiante de la carrera de ingeniería industrial. Si bien este entrevistado realizaba pasantías en diversas empresas automotrices a través del sistema implementado por la universidad, sostenía la esperanza y consideraba la posibilidad de desempeñarse como consultor profesional autónomo cuando se recibiese (contando, en cierta forma, con el apoyo del capital económico familiar).

Mientras tanto, los referentes con padres titulados en ejercicio en sus familias de origen, tendieron a inversiones escolares significadas como "mandatos familiares", valorando las credenciales educativas como "la única herencia que te dejan los padres". En estos casos la ocupación tiende a confluir a tal punto con la vocación en los relatos de los entrevistados ("un espacio de realización personal"), que el sostenimiento económico aparece referenciado como un elemento "secundario" que se logra por su intermedio.

En todas las trayectorias analizadas se combinan de manera eficaz las inserciones en instituciones educativas públicas (más elegidas para los niveles primario y universitario) y privadas (utilizadas para el nivel secundario, cuando no se opta por los colegios públicos preuniversitarios, con examen de ingreso).

Una breve referencia a las transformaciones de los últimos años puede enmarcar estas estrategias de inversión en capital cultural. Durante la década de 1990 se registra una fuerte expansión de las escuelas y universidades privadas, que complejiza un panorama de segmentación de la oferta, tanto pública como privada. Se fue constituyendo un sistema jerárquicamente diferenciado, según: el origen social de los alumnos, el perfil formativo de los docentes, la infraestructura de los edificios escolares o los modelos pedagógicos (Veleda, 2003). Si bien todo esto iba parejo a una expansión de la matrícula en niveles primario y secundario, no se consolidaron los efectos democratizadores por la introducción de mecanismos de compra en educación, esta vez, del lado de la demanda ${ }^{14}$. El efecto segmentador de la oferta, y crecientemente de la de-

${ }^{14}$ Entre esos criterios, Veleda (2003) menciona los exámenes de ingreso en escuelas secundarias, que a su vez requerían de un curso preparatorio para aprobarlo; o el pago de cuotas cooperadoras, etc. Estos criterios introdujeron un efecto discriminatorio, supeditando cada vez más la calidad educativa al poder de compra o al poder de movilizar influencias para conseguir una plaza. "A partir de ese momento [1990] el sistema educativo funciona según la lógica de mercado y las escuelas se transforman en mercancías que las familias adquieren de acuerdo a su capacidad de consumo. En el mismo sentido, las escuelas "seleccionan" de manera oculta a su propia matrícula" (Del Cueto y Luzzi, 2008: 64). 
manda ${ }^{15}$, generó una ruptura con la homogeneidad formal del sistema educativo, delineando la generación de circuitos escolares.

Las carreras universitarias o terciarias cursadas por los entrevistados (ingeniería, derecho, historia, martillero público, magisterio) fueron complementadas, completadas o profundizadas con estudios de posgrado y cursos de especialización posteriores (por ejemplo, especializaciones pedagógicas para los insertos en el campo de la docencia), como así también instancias formativas con becas en el extranjero (Brasil, Estados Unidos).

En general, opera una suerte de creencia práctica -en el sentido de inversión o ilussio (Bourdieu y Wacquant, 2005) - en la lentitud del proceso formativo, que continúa mucho más allá de las instancias de formación superior (terciaria o de grado). Esta marcha de constantes inversiones en certificación escolar sólo comienza a menguar cuando los agentes logran posiciones laborales consolidadas (titularidad de cargos en docencia, concursos ganados en el sistema judicial, etc.).

La lentitud y perseverancia en los procesos formativos se corresponde con los tiempos de acumulación del capital escolar, a largo plazo, estableciendo una suerte de homología práctica entre los campos laboral y escolar en las trayectorias de los referentes en estas familias. Por ello, esta "paciencia" y "constancia" se trasladaría del mercado escolar al mercado de trabajo en búsquedas de inserciones laborales adecuadas a las expectativas formadas.

\section{Entre los "saberes prácticos", la titulación protectora y el control de la sociabilidad}

Tomando en cuenta las tendencias planteadas previamente en torno a las asociaciones estructurales resultantes del procesamiento de datos estadísticos, las titulaciones escolares no constituyen el basamento fundamental de las trayectorias laborales de los referentes familiares entrevistados correspondientes a la clase trabajadora. Sus antecesores (padres y madres de los referentes) accedieron a nivel primario, especialmente aquellos con origen rural, mientras que la generación de los referentes presenta una acumulación de capital escolar apenas mayor, llegando a secundario incompleto y completo -en el caso de algunas mujeres-. Esta mayor acumulación coincide con los mentados procesos

\footnotetext{
${ }^{15}$ Algunas investigaciones (Del Cueto, 2004; Veleda, 2003) han indagado las elecciones de los padres de las escuelas para sus hijos. De estas investigaciones resalta la importancia concedida al origen social predominante del alumnado. También las escuelas utilizan criterios de selección de su alumnado, dando lugar a la circularidad de que "las mejores escuelas sean aquellas a las que van los mejores alumnos" (Tenti Fanfani, en Veleda, 2003).
} 
de democratización del acceso al sistema educativo, que conllevan a su vez procesos de devaluación por exceso en las titulaciones escolares.

El capital cultural en las trayectorias de los referentes, cónyuges e hijos de familias de clase trabajadora adopta mecanismos de acumulación en formato incorporado, como oficios aprendidos, heredados (es el caso de la mecánica y de la construcción) o apropiados en trayectos e instancias formativas alternativas (por fuera del sistema escolar). La referencia a "cursos de capacitación" aparece como una opción recurrente -particularmente válida para las mujeres, comúnmente sobrecargadas de responsabilidades domésticas entre las familias de esta clase $\mathrm{e}^{16}$ - con la meta de adquirir formación directamente dispuesta para la inversión laboral de los saberes.

Este tipo de instancias formativas presenta un fuerte arreglo a los recursos materiales, temporales y simbólicos de estos agentes: escasa disponibilidad horaria, necesidades de inversión y "retorno" a corto o mediano plazo, instituciones ubicadas muchas veces en los mismos barrios de residencia de las familias, etc. Además de adaptarse a las condiciones disponibles, la apuesta por estas instancias formativas encuentra razonabilidad también en los espacios de valorización predilectos para las familias de esta clase (al menos para sus integrantes peor posicionados: mujeres y, en menor medida, jóvenes). La inversión de las competencias y certificaciones alternativas y de menor duración se orientan a ser valoradas en algunos de los segmentos precarios más típicamente ligados a las ocupaciones de clases populares, pero ofreciendo una suerte de plus-de-cualificación laboral en estos mismos sectores de actividad (cursos de peluquería, podología, reiki, repostería) que permiten, si no acceder a mejores posiciones dentro de la misma rama, al menos adquirir mayor autonomía y hasta "independizarse" con emprendimientos propios.

La fuerte apuesta en estas familias por la educación técnica ${ }^{17}$ (aunque no sea exclusiva de esta clase social) remite a una forma homóloga de arreglos

${ }^{16}$ La sobrecarga de las mujeres en las tareas de reproducción doméstica no es una característica exclusiva de esta clase. Sin embargo, la mayor presencia de integrantes menores de 10 años en estas familias y el carácter más numeroso de sus hogares, intensifica el volumen de las tareas domésticas y lo vuelve particularmente relevante en la clase trabajadora.

${ }^{17}$ Si bien la escuela técnica en Argentina surgió de modo estratificado (con escuelas industriales para las clases medias y escuelas de artes y oficios para los hijos de obreros), constituyó un canal de movilidad para los hijos de obreros calificados, empleados y cuentapropistas (Gallart, 2006). Sin embargo, en las últimas décadas también se vio afectada por la segmentación. En la ciudad de Córdoba esta oferta presenta diversidad de cobertura por niveles y orientaciones, y está cubierta por los sectores público y privado (Zabala, 2015). En este último se presentan dos instituciones con gran prestigio: el Instituto Renault (iniciativa de la fábrica) y el Instituto Técnico Villada, de la orden salesiana (Jiménez, 2016). 
entre titulación, temporalidad y saberes incorporados. En la generación de los referentes implica un recurso estratégico fundamental valorizado en aquellas trayectorias con inserción laboral en ramas con fuerte componente técnico, como los casos de construcción e industria, dos de las ramas estadísticamente asociadas a los puestos de los referentes de hogar en esta clase. En el caso de la industria (junto con el transporte y la logística), se constituye en una opción relativamente atractiva en cuanto a condiciones salariales, de contratación, de negociación sindical y seguridad social, en contraposición al resto de ocupaciones recurrentes entre trabajadores de clases populares (empleo doméstico, construcción, venta ambulante, etc.). Como han mostrado algunos estudios etnográficos clásicos (Willis, 1988; Beaud y Pialoux, 2015) y locales (Noel, 2009), el des-arreglo disposicional y normativo-interaccional que existe entre la escena escolar y la cultura de las clases populares queda en suspenso en el caso de la escuela técnica, por sus dinámicas y criterios de valoración del conocimiento (orientado prácticamente a la producción) mucho más afines a los patrones valorativos de los orígenes sociales de sus estudiantes. En este sentido, la continuidad de la apuesta por la educación técnica en las estrategias escolares de los hijos de estas familias podría basarse, también, en cierta afinidad electiva por las modalidades de incorporación y valoración del capital cultural prácticamente dispuesto, siguiendo la lógica de transmisión no sólo de los recursos culturales y simbólicos sino, al mismo tiempo, de las condiciones y las herramientas para su apropiación y valorización.

Paralelamente, el fuerte peso relativo del capital social en las trayectorias laborales de muchos de los entrevistados (redes laborales familiares, cartera de clientes estable y heredada, construcción de lazos de confianza en el trabajo doméstico, etc.), aparece como un criterio decisorio y un principio de justificación recurrentemente esgrimido por los entrevistados en torno a sus elecciones y cambios en la orientación escolar de sus hijos. Muchos referentes narran el traspaso de sus hijos (frecuentemente los hermanos menores) desde escuelas de gestión pública a escuelas de gestión privada como una inversión colectiva (familiar) en la resolución de los problemas de su rendimiento escolar. A menudo esta opción implica un conjunto de renuncias, desde prestaciones monetarias (como la Asignación Universal por Hijo, que se percibe solamente en el caso de niños que asisten a instituciones públicas) hasta trayectos de movilidad espacial más complejos para asistir a escuelas que se ubican por fuera del barrio de residencia familiar y sin transporte público directo.

$\mathrm{Al}$ ser consultados por las razones en los cambios de la escolarización de sus hijos los entrevistados son puestos, más allá de cualquier vigilancia epistemológica posible, en situación de justificar sus acciones y de exponer la racio- 
nalidad de sus elecciones. En general tienden a marcar fuertes discontinuidades entre las escuelas "públicas" y "privadas" (algunas de ellas, confesionales), aunque basados en criterios más vinculados a cuestiones de "conducta" o "actitudinales" que a patrones de evaluación estrictamente "académicos": la "mentalización" de los estudiantes de las escuelas privadas para continuar con su formación una vez terminada la escolaridad obligatoria; la "exigencia" (actitudinal) que estas instituciones requieren y la "contención social" que ofrecen (valorando fundamentalmente el intercambio y diálogo y la receptividad de la escuela con los aportes o intervenciones de los padres). La disciplina y el respeto como valores de las instituciones privadas se contraponen a la caracterización de los problemas de las escuelas públicas, signadas por la "vagancia", las "banditas" y un mal "ambiente"18.

Las justificaciones de las entrevistas delinean sentidos de lo escolar como espacio de aprendizaje de conocimientos, pero fundamentalmente de actitudes y disposiciones comportamentales (portarse bien, respetar), asignando a la institución educativa funciones estereotipadas de normalización y civilización (Elias, 1988). Las argumentaciones nativas específicamente ancladas en el ámbito académico se ven desdibujadas ante el peso de la valoración de prácticas institucionales, las "juntas", el "ambiente" social y la inculcación de "hábitos" y "actitudes" culturales.

En este sentido, y en relación al importante peso relativo del capital social en sus trayectorias laborales, estas elecciones ponen de manifiesto el esfuerzo y la apuesta por la regulación paterna de la sociabilidad de sus hijos, y con ello, la construcción de una estrategia defensiva contra lo que implica entre los jóvenes de estas familias -particularmente entre las fracciones menos capitalizadas de las clases populares- el capital simbólico negativo hacia dentro del barrio y las redes vecinales, ámbito territorial vital de apuestas y búsquedas laborales para estos agentes (Alhambra Delgado, 2012; Kessler y Dimarco, 2013).

En estos relatos de prácticas (Bertaux, 2005) los referentes afirman su compromiso y su sacrificio por la educación de los hijos, exponiendo la visión y el diagnóstico nativo sobre las transformaciones en las exigencias de capital escolar en el mercado laboral en las últimas décadas: "antes" los trabajadores

\footnotetext{
${ }^{18}$ Este conjunto de percepciones se enmarca en un contexto en el que una serie de discursos (políticos, mediáticos y docentes) de larga data han instalado como "problema social" -y con cierto clima de "pánico moral" (Cohen, 1972; Hall et al., 1978)- el ingreso de la "cuestión social" en la escuela pública y el consiguiente "desvío" respecto de su función esencial: la enseñanza y el saber "puros". Se filtrarían en la escuela nuevas dinámicas "impuestas" y "externas": la "asistencia social", la "contención", la distribución de recursos económicos y la "política" (Kessler, 2002; Noel, 2009; Grimson y Tenti Fanfani, 2014).
} 
entraban a la fábrica con nivel "primario" completo, mientras que "hoy" un secundario "no te alcanza", pero es un medio para un trabajo mejor. Esto también diferencia la apuesta por las instituciones privadas: varios de los entrevistados sostienen que, mientras que egresando de una escuela pública "no podés aspirar a mucho más que a una changa", en las privadas te "mentalizan" para que "sigas una carrera". Si bien no es nuestro objeto específico de indagación, la comparación entre la escuela de "antes" y de "hoy" suele disparar procesos de incomprensión generacional (Beaud y Pialoux, 2015): aun cuando los agentes reconocen la devaluación de los recursos culturales en relación al pasado y aspiran a mayores acumulaciones para asegurar sus posiciones, las condiciones para dichas inversiones continúan atadas a ritmos y temporalidades distintas a las dominantes en el mercado escolar.

Por todo ello, la modalidad de capital cultural incorporado como competencia técnica (y aplicable) aparece como el patrón dominante en las estrategias escolares y laborales de las familias de clase trabajadora. Los relatos sobre experiencias de aprendizaje en el trabajo asumen un formato "práctico" y usualmente en oposición al saber de tipo "teórico": el oficio (construcción, mecánica, industria) se aprende "haciendo", "mirando y preguntando". El conjunto de estas apreciaciones y justificaciones pone en valor la iniciativa y la curiosidad como herramientas laborales claves: "mi deseo de trabajar superaba el de perfeccionarme", declara uno de los entrevistados, mecánico de ocupación, que había heredado el oficio de su padre.

Contrario a lo que indica el prejuicio de "cortoplacismo" que pesa sobre las familias de clases populares, el sacrificio moral y financiero de los padres para sostener la escolaridad de sus hijos adquiere razonabilidad con una proyección de retornos educativos a muy largo plazo en el aseguramiento del destino escolar, laboral y social de los hijos (Beaud y Pialoux, 2015): para que su vida no sea "tan sacrificada", "se debe" invertir "en los hijos" -privándose de formas de gastos estrictamente materiales, de placer u ocio como "autos, casas, etc."-. Esta lógica rehabilita la pregunta por la creencia -entre los referentes de esta clase- en el carácter sustancial de las credenciales educativas y en su eximición de los procesos de devaluación: "a donde mis hijos vayan, si se reciben, siempre van a tener el título".

\section{CONCLUSIONES}

El desplazamiento de la mirada desde los retornos educativos a las historias familiares de acumulación, inversión y valorización de los capitales culturales pone de manifiesto la necesidad de revisar y matizar los análisis de reducción 
de las desigualdades, concomitantes muchas veces al relato celebratorio del crecimiento de las clases medias en América Latina en las últimas décadas.

La reconstrucción de las trayectorias familiares nos permitió poner en tensión las estrategias escolares y la sedimentación histórica de inserciones laborales muy disímiles en las familias de cada clase, en las que los usos y los valores de las titulaciones habían adquirido sentidos y tendencias objetivas profundamente diferentes.

Contra ciertos prejuicios instalados acerca del valor de lo escolar entre las familias de clase trabajadora, nuestra investigación indicó importantes confluencias inter-clase en las inversiones escolares, en el involucramiento familiar (particularmente femenino) en la gestión de la vida escolar de los hijos y en los esfuerzos sacrificiales por el sostenimiento o la mejora de la calidad educativa de los integrantes de la familia (la elección de las "mejores opciones" en el mercado escolar, invirtiendo recursos materiales y simbólicos relevantes para todas estas familias).

La temporalidad como recurso y configuración de estas inversiones, sin embargo, marca puntos de inflexión. Las familias de clase media definen inversiones escolares constantes, tendientes al capital cultural institucionalizado y al largo plazo de acumulación, bajo la creencia práctica y la figura del "mandato" por el estudio. A su vez estas inversiones adquieren legibilidad en trayectorias laborales de los referentes y sus antecesores, que tienden a la especialización o a carreras burocráticas con mecanismos de acceso, consolidación y promoción anclados en las credenciales escolares con mayor legitimidad en el mercado.

Las familias de clase trabajadora, en cambio, atraviesan procesos de acumulación de capital cultural mucho más recientes en el tiempo, signadas por la democratización creciente en el acceso al sistema educativo, y esto parece marcar de manera relevante su experiencia y significación de lo escolar. Sus procesos formativos tienden a la acumulación en formato de capital cultural incorporado o práctico (tanto en las instituciones educativas como en la experiencia laboral misma), en instancias alternativas (cursos) y más orientadas a la diversificación que a la especialización.

El capital social aparece como un patrón de confluencia en la valoración y definición de las estrategias de escolaridad para los hijos de familias de ambas clases, aunque de maneras distintas. Puesto de manifiesto en la distinción nativa de las gestiones "pública" y "privada" de las instituciones educativas y en la argumentación acerca de sus elecciones escolares, en las familias de clase media la escuela aparece como un espacio de acumulación de capital social con pretensión de ascenso, de "tirar para arriba" aspiraciones, actitudes y contac- 
tos para sus hijos. Las familias de clase trabajadora, en cambio, sostienen discursos de protección, donde el control de la sociabilidad de sus hijos y la evitación del estigma aparecen como necesidades vitales en contextos de inserción laboral y oficios con un gran peso relativo de redes vecinales de intercambio y clientelas heredadas o personalizadas.

Las significaciones de las apuestas educativas y las titulaciones en las familias de clase media, en este sentido, asumen desde formas más instrumentales a sentidos más estrictamente vocacionales, pero sosteniendo valoraciones adaptadas a modos de reproducción familiar orientados principalmente a la realización del capital cultural. En este marco, la educación se interpreta como la "única herencia que dejan los padres".

Los referentes de las familias de clase trabajadora, en cambio, parecen definir estrategias escolares bajo interpretaciones relativamente sustancializadas de las titulaciones escolares, haciendo emerger su valor proteccionista como recurso en el mercado de trabajo: "donde vayan, tendrán la educación".

En este sentido, se podría avanzar sobre la hipótesis de una mayor ruptura inter-generacional entre las estrategias escolares de las familias de clase trabajadora (mucho más orientadas a la consecución de títulos para sus hijos como protecciones de la inestabilidad estructural que los aqueja) que en las familias de clase media (orientados a la acumulación permanente con la expectativa de reproducir carreras de inserción calificada y concordante con sus especialidades formativas). En esta dirección, se precisaría explorar cierta divergencia en el sentido práctico de los agentes acerca de la devaluación de cualquier forma de capital cultural. Si buena parte de la denominada "disminución de los retornos educativos" se basaba en una orientación del mercado laboral hacia la mano de obra de menor calificación, las recientes transformaciones en las políticas económicas en Argentina cubren con un manto de interrogantes la posibilidad de estos sectores de sostener una continuidad en las estrategias que habrían habilitado dicha disminución de las brechas.

Al mismo tiempo, los contrapuntos entre ambas clases pusieron en evidencia valoraciones diferenciales entre las familias (incluso entre aquellas que presentaban trayectorias diferentes dentro de la misma clase). Los sentidos académicos, instrumentales, desinteresados y prácticos asignados al saber y la titulación escolar, así como las funciones académica, disciplinaria y formadora de contactos atribuidas a la vida escolar se traman con trayectorias laborales que han puesto a jugar estos capitales en segmentos del mercado de trabajo cuyas lógicas de selección son diferentes (desde las redes vecinales de reciprocidad personalizada hasta los concursos públicos de acceso a los puestos estatales). 
En conjunto, esta amplia gama de procesos parece modificar las distancias en el espacio de las clases, aunque con "tendencias contrapuestas" en distintas áreas de la vida social. La configuración de la desigual distribución del capital cultural -que articula en la lógica de su realización al mercado escolar y al mercado laboral- habilita, en la lectura de las trayectorias familiares de largo plazo, una interpretación en términos de reconfiguración y reproducción de las desigualdades. Esta se pone de manifiesto en la transmisión simultánea de los recursos y de las herramientas para su valorización, de los capitales y de los habitus que los ponen a jugar en apuestas, inserciones y "retornos" con complejos equilibrios y gestiones colectivas de la vida familiar.

\section{BIBLIOGRAFÍA}

Alhambra Delgado, M. (2012). "La marginalidad avanzada como uno de los semblantes del capital simbólico negativo". En I. González Sánchez (Ed.), Teoría social, marginalidad urbana y estado penal: aproximaciones al trabajo de Loïc Wacquant. Madrid: Dykinson, 135-150.

Baranger, D. (2000). "Sobre estructuras y capitales: Bourdieu, el análisis de redes y la noción de capital social". Avá, 2, 41-63.

Baranger, D. (2004). Epistemología y metodología en Pierre Bourdieu. Buenos Aires: Prometeo.

Beaud, S. y Pialoux, M (2015). Repensar la condición obrera. Investigación en las fábricas de Peugeot de Sochaux Montbéliard. Buenos Aires: Ministerio de Trabajo, Empleo y Seguridad Social - Centre National du Livre - Antropofagia.

Benza, G. (2014). El estudio de las clases medias desde una perspectiva centrada en las desigualdades en oportunidades de vida. México: Cuadernos de Investigación en Desarrollo, Universidad Nacional Autónoma de México.

Benza, G. (2016). "La estructura de clases argentina durante la década 2003-2013". En G. Kessler (Comp.), La sociedad argentina hoy. Radiografia de una nueva estructura. Buenos Aires: Siglo XXI, 111-140.

Bertaux, D. (1995). "Social Genealogies Commented On Compared: An Instrument for Observing Social Mobility Processes in the "Longue Durée". Current Sociology, 43, 69-88.

Bertaux, D. (2005). Los relatos de vida. Perspectiva etnosociológica. Barcelona: Bellaterra. Bourdieu, P. (1997). Razones prácticas. Sobre la teoría de la acción. Barcelona: Anagrama. Bourdieu, P. (1998). La distinción: criterios y bases sociales del gusto. Madrid: Taurus. Bourdieu, P. (2010). El sentido práctico. Buenos Aires: Siglo XXI.

Bourdieu, P. (2011). Las estrategias de la reproducción social. Buenos Aires: Siglo XXI. Bourdieu P. y Wacquant, L. (2005). Una invitación a la sociología reflexiva. Buenos Aires: Siglo XXI.

Cohen, S. (1972). Folk Devils and Moral Panics. The creation of the Mods and Rockers. Nueva York: Routledge. 
Del Cueto, C. M. (2004). "Estrategias educativas de las clases medias en urbanizaciones cerradas del Gran Buenos Aires". Espiral, XI, 31, 249-276.

Del Cueto y Luzzi, M. (2008). Rompecabezas. Transformaciones en la estructura social argentina (1983 - 2008). Buenos Aires: Universidad Nacional General Sarmiento - Biblioteca Nacional.

Elias, N. (1988). El proceso de la civilización. Investigaciones sociogenéticas y psicogenéticas. México: Fondo de Cultura Económica.

Freyre, M. L. y Assusa, G. (2014). "Clases sociales y prácticas laborales desde la perspectiva de las estrategias de reproducción social”. Desenvolvimento em Questão. 12 (27), 5-41.

Gallart, M. A. (2006). La escuela técnica industrial en Argentina: ¿un modelo para armar? Montevideo: Cintefort-OIT.

Giovine, M., y Jiménez, C. I. (2016). "Transformaciones del mercado escolar en el espacio social de Gran Córdoba. 2003-2011”. En A. Gutiérrez y H. Mansilla (Comp.) El espacio social de las clases y los instrumentos de reproducción social. Córdoba: UNC, 149-206.

Goldthorpe, J. (1992). "Sobre la clase de servicio, su formación y su futuro", Zona Abierta, 59-60, 229-263.

Grimson A. y Tenti Fanfani, E. (2014). Mitomanías de la educación argentina. Crítica de las frases hechas, las medias verdades y las soluciones mágicas. Buenos Aires: Siglo XXI.

Gutiérrez, A. (2005). Pobre’ como siempre. Estrategias de reproducción social en la pobreza. Córdoba: Ferreyra.

Gutiérrez, A. (2010). "A modo de introducción. Los conceptos centrales en la sociología de la cultura de Pierre Bourdieu”. En P. Bourdieu, El sentido social del gusto. Elementos para una sociología de la cultura. Buenos Aires: Siglo XXI, 9-18.

Gutiérrez, A. y Mansilla, H. (2015). "Clases y reproducción social: el espacio social cordobés en la primera década del siglo XXI". Política y Sociedad, 52 (2), 409-442.

Hall, S., Critcher, C., Jefferson, T., Clarke, J., Roberts, B. (1978). Policing the crisis. Mugging, the state and law and order. Londres: The Macmillan Press.

Jiménez, C. I. (2016). "Transmisión intergeneracional y trayectorias sociales. Las clases medias cordobesas vinculadas a la industria automotriz", Trayectorias, 42, 3-27

Kessler, G. (2002). La experiencia escolar fragmentada. Estudiantes y docentes en la escuela media en Buenos Aires. Buenos Aires: IIPE-UNESCO.

Kessler, G. (2014). Controversias sobre la desigualdad. Argentina, 2003-2013. Buenos Aires: Fondo de Cultura Económica.

Kessler, G. (2015). "Desigualdad en América Latina ¿un cambio de rumbo?". Carta mensual INTAL. N 221. BID.

Kessler, G., y Dimarco, S. (2013). "Jóvenes, policía y estigmatización territorial en la periferia de Buenos Aires”. Espacio abierto, 22 (2), 221-243.

Lahire, B. (2004). El hombre plural: Los resortes de la acción. Barcelona: Bellaterra. 
López-Roldán, P. (1996). "La construcción de una tipología de segmentación del mercado de trabajo". Papers, 48, 41-58.

Lustig, N., López-Calva, L. F. y Ortiz-Juárez, E. (2011). "The decline in inequality in Latin America: How much, since when and why". ECINE 2011-211. Society for the Study of Economic Inequality. Working Papers.

Martín Criado, E. (1998). Producir la juventud. Crítica de la sociología de la juventud. Madrid: Itsmo.

Mauger, G. (2013a). "Juventude: idades da Vida e Geraçoes". Dados. Revista de Ciências Sociais, 56 (1), 169-183.

Mauger, G. (2013b). "Modos de generación" de las "generaciones sociales"”. Sociología Histórica, 2, 131-151.

Neffa, J. C., Oliveri, M. L., Persia, J. (2010). "Transformaciones del mercado de trabajo en la Argentina: 1974-2009”. En J. C. Neffa, D. Panigo y P. E. Pérez (Comps.), Transformaciones del empleo en Argentina. Estructura, dinámica e instituciones. Buenos Aires CICCUS, 19-52.

Noel, G. (2009). La conflictividad cotidiana en el escenario escolar: una perspectiva etnográfica. San Martín: UNSAM.

Palomino, H. y Dalle, P. (2012). "El impacto de los cambios ocupacionales en la estructura social de la Argentina: 2003-2011". Revista del Trabajo - Nueva Época, 8 (10), 205-224.

Salvia, A. y Vera, J. (2013). "Heterogeneidad estructural, calidad de los empleos y niveles educativos de la fuerza de trabajo en la Argentina post reformas estructurales (2004-2007-2011)". $11^{\circ}$ Congreso Nacional de Estudios del Trabajo, Buenos Aires, 7, 8 y 9 de agosto de 2013. http://www.aset.org.ar/2013/ponencias/p3_Salvia.pdf (consultado el 28 de julio de 2016).

Savage, M., Devine, F., Cunningham, N., Taylor, M., Yaojun, L., Hjellbrekke, J., Le Roux, B., Friedman, S. y Miles, A. (2013). "A New Model of Social Class? Findings from the BBC's Grat British Class Survey Experiment. Sociology, 47(2), 219-250.

Thompson, E. P. (1989). La formación de la clase obrera en Inglaterra. Barcelona: Crítica. Torrado, S. (1998). Familia y diferenciación social. Cuestiones de método. Buenos Aires: Eudeba.

Veleda, C. (2003). "Mercados educativos y segregación social. Las clases medias y elección de la escuela en el Conurbano Bonaerense". Documento de Trabajo $N^{o} 12$, CIPPEC.

Vommaro, G. y Wilkis, A. (2015). "Por una lectura práctica. A propósito de Repensar la condición obrera". En S. Beaud y M. Pialoux, Repensar la condición obrera. Investigación en las fábricas de Peugeot de Sochaux Montbéliard. Buenos Aires: Ministerio de Trabajo, Empleo y Seguridad Social - Centre National du Livre - Antropofagia.

Willis, P. (1988). Aprendiendo a trabajar: como los niños de la clase obrera consiguen trabajos de clase obrera. Madrid: Akal. 
Zabala, E. (2015). "La educación técnico-profesional como factor de desarrollo estratégico. Panorama actual y balances frente a nuevos escenarios". Cuestiones de Población y Sociedad, 5 (5), 59-69.

\section{FUENTES}

INDEC, Base usuario ampliada de la Encuesta Permanente de Hogares, Tercer trimestre 2003 y 2013, Región Gran Córdoba, disponible en <www.indec.mecon.gov.ar> [consulta: 12 de agosto de 2016].

GONZALO ASSUSA es Licenciado en Sociología por la Universidad Nacional de Villa María y Doctor en Ciencias Antropológicas por la UNC. Actualmente se desempeña como becario posdoctoral en el Instituto de Humanidades de CONICET-UNC. Investiga sobre desigualdad de clases y diferenciación simbólica en la sociedad cordobesa contemporánea. Ha publicado artículos individuales y colectivos en revistas académicas de Argentina, Chile, Brasil, Colombia y España y libros o capítulos de libro editados por Miño y Dávila, CLACSO, GEU y Eduvim.

CECILIA INÉS JIMÉNEZ ZUNINO es Licenciada en Sociología por la Universidad Nacional de San Juan (Argentina) y Doctora en Sociología por la Universidad Complutense de Madrid (España). Se desempeña como Investigadora del Instituto de Humanidades de CONICET-UNC, con temas sobre desigualdad social y trayectorias de clases medias en Córdoba. Ha publicado múltiples artículos y capítulos de libros sobre desclasamiento, migraciones y estrategias de reproducción social de las clases medias y participado en investigaciones en España y Argentina.

Recibido: $13 / 08 / 2016$

Aceptado: 23/07/2017

\section{(c) (1) Licencia Creative Commons Reconocimiento (CC BY 4.0)}

